\title{
Operating microscopes: past, present, and future
}

\author{
Kutluay Uluç, M.D., Gregory C. Kujoth, Ph.D., and Mustafa K. Başkaya, M.D. \\ Department of Neurological Surgery, University of Wisconsin, Madison, Wisconsin
}

\begin{abstract}
The operating microscope is a fixture of modern surgical facilities, and it is a critically important factor in the success of many of the most complex and difficult surgical interventions used in medicine today. The rise of this key surgical tool reflects advances in understanding the principles of optics and vision that have occurred over centuries. The development of reading spectacles in the late 13th century led to the construction of early compound microscopes in the 16th and 17th centuries by Lippershey, Janssen, Galileo, Hooke, and others. Perhaps surprisingly, Leeuwenhoek's simple microscopes of this era offered improved performance over his contemporaries' designs. The intervening years saw improvements that reduced the spherical and chromatic aberrations present in compound microscopes. By the late 19th century, Carl Zeiss and Ernst Abbe ushered the compound microscope into the beginnings of the modern era of commercial design and production. The introduction of the microscope into the operating room by Nylén in 1921 initiated a revolution in surgical practice that gained momentum throughout the 1950s with multiple refinements, the introduction of the Zeiss OPMI series, and Kurze's application of the microscope to neurosurgery in 1957. Many of the refinements of the last 50 years have greatly improved the handling and practical operation of the surgical microscope, considerations which are equally important to its optical performance. Today's sophisticated operating microscopes allow for advanced real-time angiographic and tumor imaging. In this paper the authors discuss what might be found in the operating rooms of tomorrow. (DOI: 10.3171/2009.6.FOCUS09120)
\end{abstract}

$\begin{array}{llllll}\text { KEY WoRdS } & \bullet & \text { operating microscope } & \text { history } & \bullet & \text { loupe } \\ \text { microscope } & \bullet & \text { optic } & \text { microsurgery }\end{array}$

\section{Early Theories of Vision}

$\mathrm{V}$ ISUAL perception is the ability to interpret the information conveyed by light reaching the eye. There were 2 major theories explaining visual perception in the ancient world. One theory was the emission (or extramission) theory, championed by Euclid of Alexandria (circa 325-265 BC) and Claudius Ptolemaeus, better known as Ptolemy (circa AD 90-168), which claimed that vision occurs when rays radiating from the eyes are intercepted by visual objects..$^{21,56}$ This view was challenged by the intromission theory, supported by Aristotle (384-322 BC) and later by Claudius Galenus (AD 130-201), better known as Galen of Pergamum. The intromission theory held that vision occurs when rays radiating from the observed objects enter the eyes. ${ }^{38,57}$ In the 1030s, Ibn al-Haytham (aka Alhazen or Alhacen) (AD 965-1039) refined intromission theory into the modernly accepted vision theory, in which the eye perceives the light that is reflected from objects and moreover, argued that visual perception occurs in the brain rather than the eye. ${ }^{21,38}$

\section{Optics and Magnification}

In 1849, the Nimrud Lens (aka Layard lens) was found by British archeologist Sir John Austen Henry
Layard in Nimrud, an ancient Assyrian city (aka Nimrod). The Nimrud lens (made circa 7th century BC) is an oval rock crystal that is believed to have been used as a magnifying glass. This use of the crystal was originally inferred from the observation that the Assyrians described Saturn as a god surrounded by serpents, which some argued was not possible without observing Saturn's rings. This interpretation, however, has not received wide acceptance and it has also been argued that the Nimrud lens was likely to have been an ornament or jewelry, as it has poor magnifying properties. Thus, claims to its use as a magnifying tool remain controversial. ${ }^{4,24,35,41,56}$

Ancient scholars recognized that objects could appear larger when viewed through refractive media (for example, water) rather than through air. Lucius Annaeus Seneca (Seneca the Younger, circa 4 BC-AD 65), tutor of the Emperor Nero, wrote: "Letters, however small and indistinct, are seen enlarged and more clearly through a globe of glass filled with water." Gaius Plinius Secundus (Pliny the Elder, circa AD 23-79) wrote in his book Naturalis Historiae that the Emperor Nero watched the gladiatorial games through a magnifying emerald..$^{27,40,44}$ Ptolemy described and calculated the refraction by water in the 2nd century AD.

Optical principles may have even been used on the battlefield in the form of lenses used to condense sunlight 


\section{K. Uluç, G. C. Kujoth, and M. K. Başkaya}

against opposing targets. In $212 \mathrm{BC}$, the mathematician Archimedes is said to have used a "burning glass" against a raiding Roman fleet commanded by Marcus Claudius Marcellus (circa 268-208 BC) which was laying siege to Syracuse (modern-day Sicily), although this claim is disputed. ${ }^{9,62}$

After the accounts of Seneca, Pliny the Elder, and Galen of Pergamum, few studies on optics are found in the historical record over the next millennium. Several notable exceptions include those of Abbas Qasim Ibn Firnas (circa AD 810-887), who made corrective lenses (reading stones), and Abu Yusuf Ya'qup Ishaq ibn al-Kindi (circa AD 801-873), who wrote "that everything in the world ... emits rays in every direction, which fill the whole world" to describe his theory of the active power of rays. Abu Sad al-Ala ibn Sahl (circa AD 940-1000), a Persian mathematician, published his understanding of how curved mirrors and lenses bend and focus light in the work On Burning Mirrors and Lenses. ${ }^{2,38,56,59}$ Alhazen, an Arabic scientist, described optical principles, intromission theory as well as the anatomy and function of the eye in a modern manner in his book Kitab al-Manazir (Book of Optics) in 1027-1040. ${ }^{38,49}$ The Western world, however, remained unaware of improvements in optics until 1267, when Roger Bacon (1214-1298) made remarkable studies on optics, mathematics, and philosophy, in part by analyzing the work of Alhazen and Aristotle. ${ }^{40,56}$

\section{Spectacles and Telescopes}

There is little doubt that the invention of spectacles led to the development of the telescope and the simple microscope. ${ }^{34}$ Sophronius Eusebius Hieronymus (circa AD 341-420; aka Saint Jerome) has been falsely credited with inventing spectacles because he had been depicted wearing eyeglasses by Renaissance artists eager to portray him as being a man of high education..$^{19,33}$ The development of reading spectacles can more accurately be attributed to Italian monks who were practiced in the art of grinding glass in the late 13th century. In 1305, a Dominican monk, Giordano da Riovalto, reported that spectacles had been invented $<20$ years previously and that he had met the inventor but failed to mention his name. Salvino D'Amato of Florence is often credited with inventing the spectacles in 1284. Some have also credited another Dominican monk, Alessandro della Spina of Pisa, as the inventor of spectacles. In any event, by 1352, spectacle use is clearly portrayed in an oil painting of Cardinal Hugh de Provence reading a book with his eyeglasses. ${ }^{22,34,56,57}$

Hans Lippershey and Hans Janssen and his son Zacharias Janssen of Middelburg, the Netherlands, were the most famous spectacle makers of the late 16th century. In 1590, Lippershey and the Janssens independently invented a telescope by placing 2 lenses within a sliding tube. ${ }^{34,40,41}$ In 1610, Tuscan physicist Galileo Galilei (1564-1642), described his "tubum opticum" which was similar to Lippershey's telescope, which used a convex objective and a concave eyepiece, but with greater optical power. ${ }^{18,28,34,57}$ According to Galileo, this telescope allowed him to "see flies as large as hens" and enabled his observations supporting Copernicus' concept of a heliocentric solar sys-
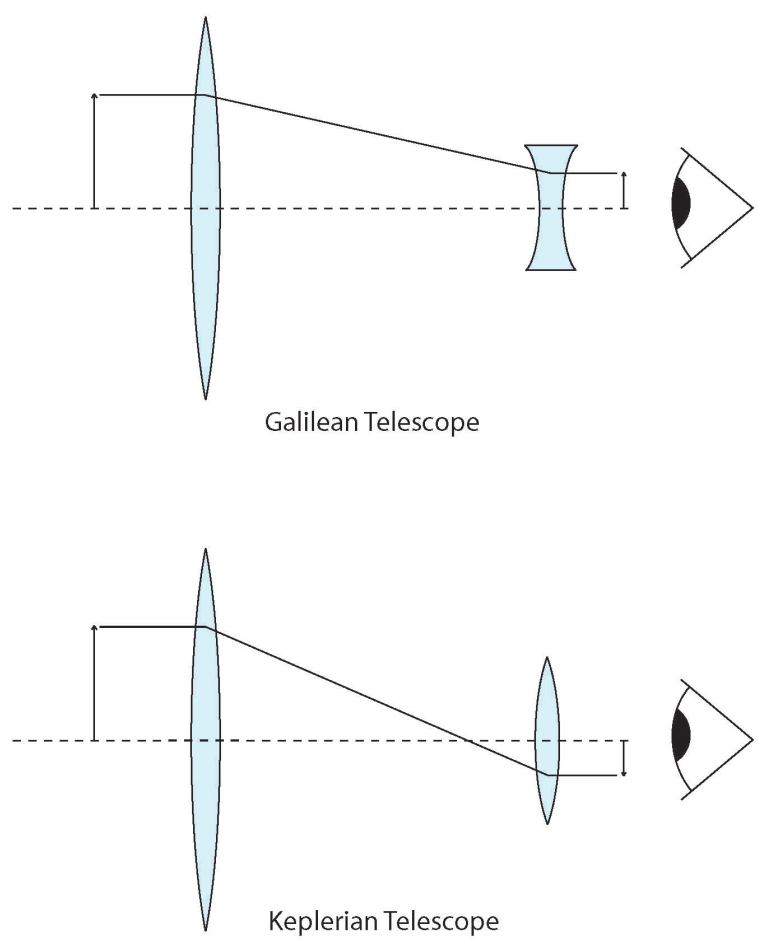

FIG. 1. Upper: Illustration of a Galilean telescope, formed by a convex and a concave lens. Lower: Illustration of a Keplerian telescope, formed by 2 convex lenses. Note that the image is inverted in a Keplerian telescope.

tem, a heretical notion at the time. (Facing trial and house arrest in 1633, Galileo recanted his views and publicly accepted the prevailing geocentric model of the universe but was reported to maintain, "Eppur Si Muove" ["Still it moves"].11,17,40)

In 1611, Johannes Kepler (1571-1630), a German astronomer and mathematician, modified Galileo's telescope design by using a convex lens in the eyepiece instead of a concave lens. Kepler's innovation inverted the image but allowed for a much wider field of view than that of Galileo's design. ${ }^{47}$ The pairing of convex and concave lens elements is today referred to as a Galilean system, while placing 2 convex lenses in a telescope is known as a Keplerian system (Fig. 1).

\section{Development of the Microscope}

A compound microscope is nothing more than a reversed telescope; Hans Lippershey, Zacharias Janssen, and Hans Janssen applied this realization to create the first compound microscope in $1590 .{ }^{57}$ Cornelius Drebbel was born in Alkmaar, the Netherlands, in 1572, and died in London, England, in 1634. When he moved to London, he brought with him a microscope made by Zacharias Janssen. Drebbel started to produce similar microscopes with a biconvex eye lens and a plano-convex objective in 1619 and later passed them off as being of his own invention. $6,46,47$

In 1624, Galileo developed a compound microscope and called it the "Occhialino," the "Little Eye." He used 2 convex lenses (as in a Keplerian system) instead of con- 


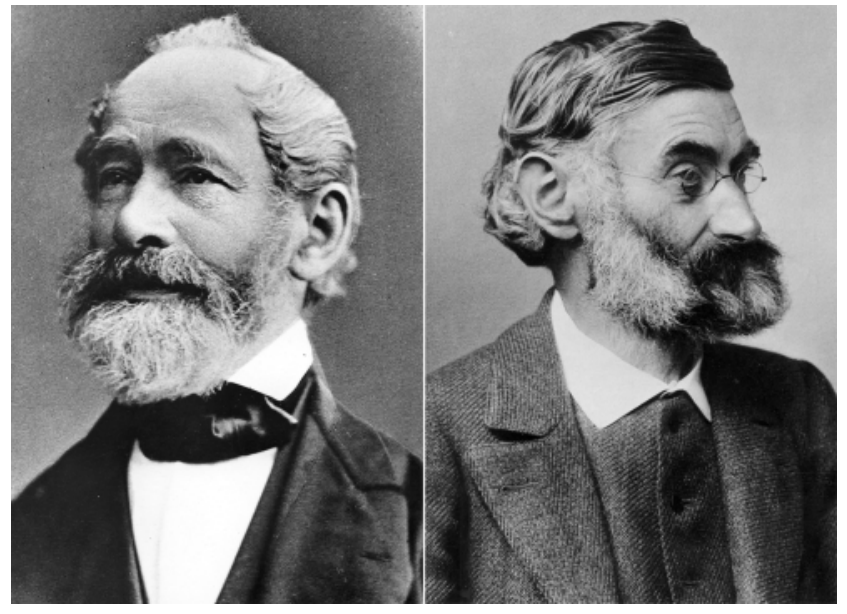

FiG. 2. Photographs of Carl Zeiss (left) and Ernst Abbe (right). Used with permission, Carl Zeiss Archives.

cave and convex lenses, as he had used in his initial telescope design. ${ }^{11,58}$ Giovanni Faber, a colleague of Galileo and a fellow member of the Academia Dei Lincei, was the first to coin the term "microscope" from the Greek words for "small" and "to look at or see."11,34 In 1660, Robert Hooke (1635-1703) used 3 lenses in a compound microscope to achieve higher magnification than that possible in earlier 2-lens designs. ${ }^{26,41}$ In 1665, Hooke published Micrographia, in which he detailed his microscopic observations and coined the term "cell." microscope and telescope were described in 1671 by Capuchin Pere Cherubin d'Orleans (1613-1697) in his book, La Dioptrique Oculare, and later he described handheld binoculars in a more comprehensive second work, La Vision Parfait in 1677.1,3,65 Joseph Giuseppe Campani (1635-1715), an Italian optician and astronomer who was an expert on grinding and polishing lenses, was the first to use a microscope (called novum microscopium) to observe human wounds, according to descriptions published in 1686 in Acta Eruditorum. ${ }^{13,20,28}$

Although early compound microscopes had good magnifying power $(\times 40-50)$, they had some significant disadvantages - the images were blurry and suffered from colored halos due to chromatic and spherical aberrations, and the microscopes became more cumbersome with each additional lens that was added. ${ }^{52}$ Anton van Leeuwenhoek (1632-1723), a Dutch tradesman, became interested in microscopes after reading Hooke's Micrographia. Leeuwenhoek managed to make the finest transportable simple microscopes of his time. He was making small but powerful lenses, producing fewer aberrations and much more powerful magnification (300-fold) when compared with compound microscopes of the era. Leeuwenhoek constructed 419 lenses and 247 microscopes, of which 9 still survive..$^{5,31,34,47}$ The quality of these microscopes earned him renown in his lifetime, and Leeuwenhoek was reluctant to share his simple methods of lens manufacturing for fear of having his accomplishments be diluted by others. ${ }^{5,31,34,47}$ Thus, the details of his lens crafting techniques would not be revealed until the 1950s, when D. L. Stong recreated Leeuwenhoek's methods. Stong even made several improvements on Leeuwenhoek's proce- dures, replacing manual polishing of tiny lenses generated from blown-glass bulbs with glass spheres produced by the breaking of thin, heated glass threads. ${ }^{32}$

Progress in correcting the optical aberrations that plagued compound microscopes began in the 1730s when Chester More Hall, a British lawyer, managed to overcome chromatic aberrations by inventing the achromatic lens, which placed concave and convex lens elements together. ${ }^{14}$ Hall attempted to keep his design private by employing 2 different companies to construct components of his microscope. However, both firms made use of the same lens maker, a man named George Bass, who deduced the achromatic design and shared it with John Dollond (1706-1761). This enabled Dollond to produce an achromatic telescope in $1759 .{ }^{14,45}$

In 1830, Joseph Jackson Lister (1786-1869), father of the famous English surgeon Lord Joseph Lister, combined flint glass lenses with crown glass lenses by placing them at specific distances from one another. Placing serial lenses at defined distances permits one lens to correct the refractive characteristics of the other. This technique allowed Lister to overcome the problem of spherical aberrations in compound microscopes. However, highly magnified images pose yet another problem: vibrations, originating from handheld use. Lister addressed this problem by directing James Smith, founder of the firm Smith, Beck \& Beck of London, to make a stand for his microscopes. ${ }^{10,12,34}$

Carl Friedrich Zeiss (1816-1888) (Fig. 2 left), eventually to become one of the most renowned names in microscope manufacturing, opened a workshop to repair optical and scientific instruments in Jena, Germany, in 1846. In 1847, Carl Zeiss produced his first microscope. He quickly enlarged his small microscope workshop by hiring more apprentices throughout 1848. By 1866, he had produced > 1000 microscopes (this number would reach 10,000 in 1886) and was awarded a gold medal at the Second Thuringian Industrial Exhibition of Trade and Industry $^{25}$ (Carl Zeiss Archives, 2009).

Carl Zeiss was a prescient enough man to understand that he needed to combine manufacturing and scientific skills to improve his microscopes. To this end, he hired Ernst Carl Abbe (1840-1905) (Fig. 2 right), Professor of Physics at Jena University (the same university where Zeiss was appointed to the position of Court Mechanic), to become the director of research of the Zeiss Optical Works in $1866^{25}$ (Carl Zeiss Archives, 2009).

Abbe proved that the optical quality of a lens could be predicted and standardized by a formula called "Abbe's Sine Condition," which could calculate the exact size, shape, and position of each individual lens in a specific microscope design. This formula allowed for the mass production of microscopes, and all Zeiss microscopes since 1872 have been produced on the basis of this formula. In 1877, Abbe manufactured the first microscope to use a homogenous (oil) immersion lens to increase the resolving power of the lens, and later in 1889 , he introduced the use of monobromonaphtalene immersion medium to increase resolving power even more ${ }^{41,54,60}$ (Carl Zeiss Archives, 2009). In 1881, Friedrich Otto Schott (1851-1935), a glass chemist, developed a new lithium-based glass, and 


\section{K. Uluç, G. C. Kujoth, and M. K. Başkaya}

he shared this with Abbe. Their partnership resulted in the introduction of a microscope with apochromatic lenses, which reduced chromatic aberrations even more than had been achieved with achromatic lenses. ${ }^{25,64}$

The development of loupes also showed significant progress during the 19th century. In the 1840 s, Parisian optician Charles Louis Chevalier (1804-1859), who specialized in achromatic binoculars and telescopes, constructed a loupe (also called Bruecke loupe) with a magnification of $6{ }^{36,42}$ In 1876, ophthalmologist Edwin Theodore Saemisch of Bonn developed the first simple loupe for surgical use. ${ }^{8}$ Carl Wilhelm Von Zehender (1819-1916), an ophthalmology professor at the University of Rostock, reported a new compound binocular device in 1886 in the journal Klinische Monatsblatter fur Augenheilkunde, of which he was the editor. Von Zehender called this device "Binokulare Cornealupe." This was a modified version of Heinrich Westien's instrument that he had built earlier for zoologist Franz Eilhard Schulze. Westien later mounted Von Zehender's device on a headband with a light source. It had a magnification of 5-6 but was not popular because of its heavy weight $(250 \mathrm{~g})$. In 1912, Moritz Von Rohr of Jena produced a much lighter loupe, which would be manufactured by Carl Zeiss, Inc. Even though this loupe had low $(2 \times)$ magnification power, it proved to be popular because of its light weight. ${ }^{7,48,53}$ In 1923, the Leitz Company produced a prismatic loupe which enabled 2 assistants, standing on each side of the surgeon, to have the same surgical view as the surgeon. ${ }^{52}$

\section{The Microscope Enters the Operating Room}

Carl Olof Nylén (1892-1978) was a young otolaryngology surgeon at the University Clinic of Stockholm. In 1921, Maiér and Lion published a paper about their observations of endolymph movements in the ear of live pigeons made by using a microscope..$^{41,43}$ Nylén was inspired by this paper and the same year decided to use a monocular Brinell-Leitz microscope, instead of a loupe, during surgery in a patient with chronic otitis media with labyrinthine fistulas. ${ }^{41,43}$

Monocular microscopes do not provide depth perception, and the absence of a light source in early designs resulted in dimness of the image with increased magnification. In 1922, Gunnar Holmgren (1875-1954), Head of the University Clinic of Stockholm (where Nylén practiced), used a binocular microscope to overcome the lack of depth perception and attached a light source to the microscope to solve the latter problem. . $^{2,41,43}$

In 1938, the issue of image vibration at high magnification was tackled in the operating room by P. Tullio and P. Calicetti, otolaryngology surgeons at the University of Parma, who constructed a heavy tripod with counterweights; this not only stabilized the image but also let the optical unit hang freely above the surgical table. Furthermore, they mounted prisms between the oculars to allow an assistant to have the same surgical view as the surgeon. ${ }^{52}$

George E. Shambaugh Jr., after working with Maurice Sourdille, a French otologist, returned to the US with an operating microscope and techniques the two had de-

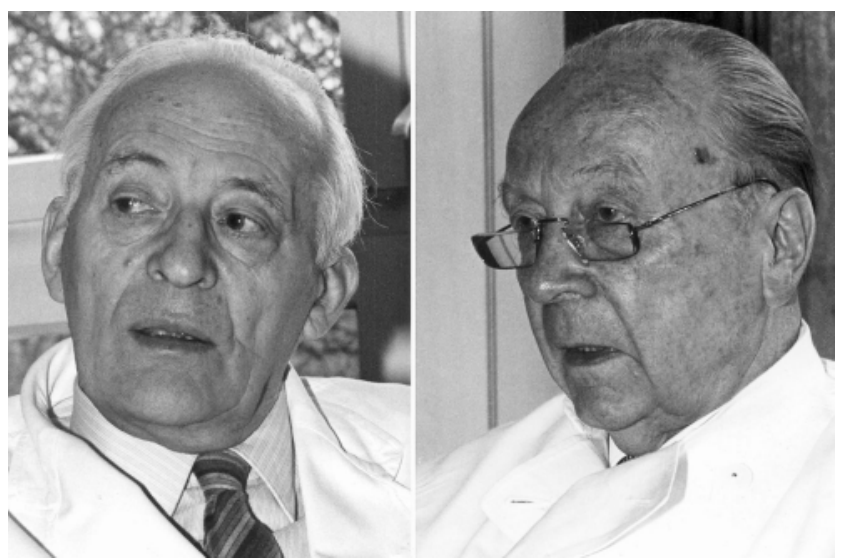

FIG. 3. Photographs of Hans Littmann (left) and Horst Wullstein (right). Copyright by Carl Zeiss Archives.

veloped together. In 1946, Richard A. Perritt, professor of ophthalmology at the University of Loyola, Chicago, borrowed the binocular surgical microscope from his friend Shambaugh, who by that time had become chairman of the Department of Otolaryngology at Northwestern University. $7,52,55$ In 1948, Perritt started to use a modification of the Bausch \& Lomb slit-lamp microscope, which had a working distance of $127 \mathrm{~mm}$ and variable magnifications of $3,5,7$, or 10.5 (achieved by changing the eyepieces). This microscope was suspending from a weighted table stand with its coaxial lighting unit and was marketed by V. Mueller \& Co. in $1951 .^{63}$

In 1952, Hans Littmann (1907-1991) (Fig. 3 left), a physicist at Zeiss in Oberkochen, started a new era by inventing a microscope capable of changing magnification without changing focal length. His design, the ZeissOpton, provided $200 \mathrm{~mm}$ of working distance and magnifications of $4,6,10,16,25,40$, or 63 selectable through a rotary Galilean system. This device was proposed for use in colposcopy, but it was not widely used due to the efficacy of Papanicolaou test in detecting cervical cancer. ${ }^{22,43,52,60,63}$

Horst L. Wullstein (Fig. 3 right), an otolaryngology surgeon from Gottingen, Germany, was not satisfied with the mechanical flexibility of the microscopes he used. To solve this problem, he built a microscope mounted on a stand equipped with a rotating arm. In 1953, Littmann benefitted from Wullstein's ideas and experience and manufactured the "Zeiss OPMI 1" (Zeiss Operating Microscope 1) (Fig. 4A), which was more stable, easier to operate, and had superior coaxial lighting than other operating microscopes in the marketplace. The OPMI 1 had 10 to $40.5 \mathrm{~cm}$ of working distance and magnifications of 2.5 and $50^{7}$ (Carl Zeiss Archives, 2009). Also during the same year, Heinrich Harms and Günter Mackensen in Tubingen adapted this microscope to ophthalmological surgery and during an Ophthalmological Congress in Buenos Aires, Jose Ignacio Barraquer used this microscope for ophthalmological surgery ${ }^{7}$ (Carl Zeiss Archives, 2009).

In 1956, Henry M. Dekking of Groningen added 3 innovations to the operating microscope: an axial illumi- 


\section{History of the operating microscope}
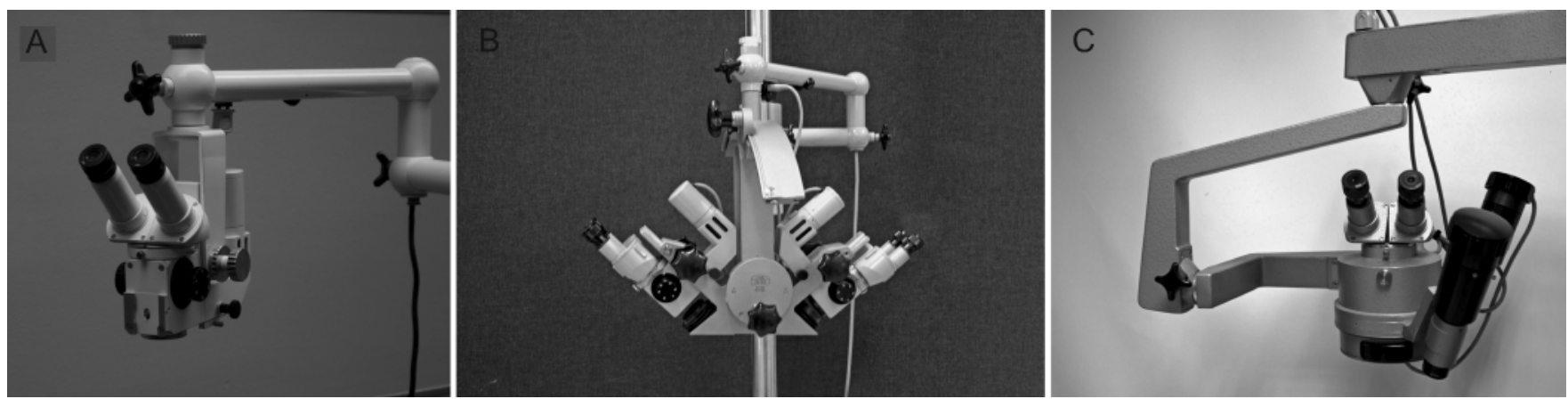

FIG. 4. Photographs of the Zeiss OPMI 1 (A), the Zeiss Diploscope (B), and the Zeiss OPMI 2 (C). Copyright by Carl Zeiss Archives.

nation, a focusing lever that could be operated with the knee, and an $\mathrm{x}-\mathrm{y}$ coordinate system with foot controls. These latter 2 developments emancipated the surgeons' hands from the slavery of the microscope's controls. Also that year, Jose Barraquer adapted a foot-operated focusing device and a slit lamp to a Zeiss microscope, allowing better visualization via side illumination, while his brother, Joaquin Barraquer, designed a ceiling-mounted microscope suspension system (attached to a special column developed by Ignacio Barraquer y Barraquer, father of Joaquin and Jose, which could also support other instruments and has found use in surgical cinematography). ${ }^{7}$

\section{Neurosurgery Adopts the Operating Microscope}

The surgical microscope entered the neurosurgical operating room in 1957 at the University of Southern California, Los Angeles, when Theodor Kurze removed a neurilemoma in cranial nerve VII from a 5-year-old patient. Kurze had been inspired by a film depicting the surgical use of a microscope by the otolaryngology surgeon William House. Even though Kurze was pleased with the outcomes of the surgeries he performed under the microscope, he found it difficult to sterilize the surgical drapes for his microscope. He later managed to solve this problem by using ethylene oxide gas (generally used for sterilizing spacecraft). ${ }^{37}$

In 1958, upon a request by Pitts Crick, the Keeler Instrument Co. manufactured a customized stand for Zeiss microscopes; this stand was quickly followed by a motorized version. By 1959, Richard C. Troutman mounted an electric hydraulic chair to a Zeiss microscope and 1 year later, installed a motorized zoom objective to his Bausch \& Lomb microscope. This same year, Dermot Pierse requested that Keeler instruments produce accessories to attach to the microscope to serve as an armrest for the surgeon and a headrest for the patient.,63 In 1964, Jose Barraquer added short ocular tubes and a slit lamp, which could be rotated on both its axis and the microscope's axis, to the OPMI 1.

Julius H. Jacobson wanted to allow a second surgeon to assist him while using magnification aids during the surgery. Jacobson and Ernesto L. Suarez had used loupes in surgeries but were not satisfied with the levels of magnification that they achieved. Therefore, Jacobson contacted
Carl Zeiss, Inc., and in 1964, Dr. Littman designed a microscope for Jacobson by adapting beam-splitter technology. This microscope was named the "Diploscope" (Fig. 4B). ${ }^{16,60,61}$

In 1965, on the advice of Jose Barraquer, Sais from Buenos Aires manufactured a prototype, in which the slit lamp, film, TV camera, and other sources of illumination rotated around the microscope. ${ }^{7}$ The same year, Zeiss manufactured the OPMI 2 (Fig. 4C), which featured motorized zoom and focus (Carl Zeiss Archives, 2009). In 1966, Jose and Joaquin Barraquer helped Hans Littman produce the OPMI 3. Later, Jose Barraquer attached several accessories to the OPMI 3; these included a rotating prism, suturing reticules in the eyepieces, a measurement scale in the slit, the rotary Galilean device of the OPMI 1 to allow changes in magnification, and a device to sterilize the microscope., ${ }^{7,8}$

Heinrich Harms was dissatisfied with the large size of the Zeiss Diploscope, which resulted in the production of the smaller OPMI 5 in 1966.' In 1968, Joaquin and Littman reported a microscope (OPMI 4) which allowed them deeper field focusing and $16-\mathrm{mm}$ motion picturing through a special telelens ${ }^{7}$ (Carl Zeiss Archives, 2009).

In 1970, Roberto Sampaolesi reported that he used manual tilting to avoid a solely perpendicular view with the microscope, and later this was achieved by using a small backup motor manufactured by Carl Zeiss, Inc. During the 1970s, Zeiss manufactured a stereoscopic coobserver accessory for the OPMI 7P/H, which allowed 3 surgeons to work simultaneously. This system also featured a high intensity light source to counteract the dimness of the image that results from the additional viewing stations ${ }^{7,23,30,50}$ (Carl Zeiss Archives, 2009).

In 1972, Yaşargil managed to overcome the unwieldiness of the operating microscope by constructing a system of adjustable multiaxis counterweights to counterbalance the microscope, a concept that had been originally suggested by Leonard I. Malis, the inventor of 2-point (bipolar) coagulation. Yaşargil attached electromagnetic brakes to each joint of the microscope to provide stability without preventing mobility. A mouth switch released the brakes, allowing the surgeon to move the microscope in both $\mathrm{x}$ and $\mathrm{y}$ axes and also controlled the focus. In 1976, Carl Zeiss, Inc., and the Contraves Company codeveloped a commercial suspension system based on Yaşargil's ideas. Diane Yaşargil later suggested a heating system 


\section{K. Uluç, G. C. Kujoth, and M. K. Başkaya}
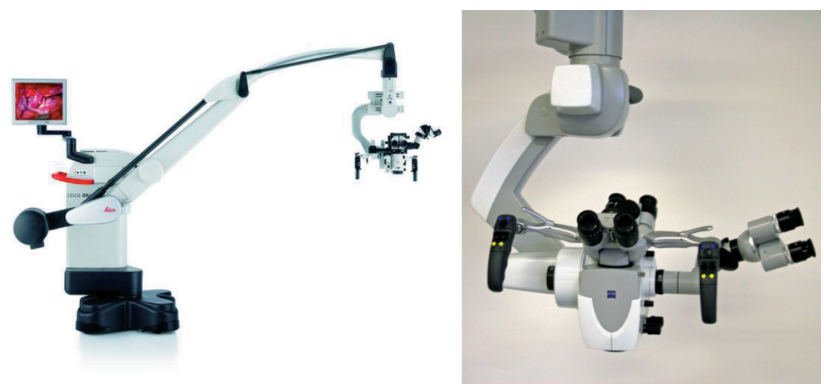

FIG. 5. Photographs. Left: The Leica M525 OH4 system. Courtesy of Leica Microsystems, Inc. Right: The Zeiss OPMI Pentero. Copyright by Carl Zeiss Archives.

for the eyepieces of the microscope to avoid fogging $23,39,66$ (Carl Zeiss Archives, 2009).

Zeiss introduced the OPMI CS in 1991 and the OPMI ES in 1994, specifically designed for neurosurgery. In 1992, Zeiss manufactured a frameless navigation device, the Multicoordinate Manipulator, as an accessory for the OPMI ES. In 1997, Zeiss introduced the OPMI Neuro and equipped this microscope with Multivision in 2000. This system projects advanced imaging techniques (for example, MR imaging, CT, and so on) directly into the eyepieces (Carl Zeiss Archives, 2009).

\section{Contemporary Operating Microscopes}

Operating microscopes have improved tremendously since they first entered the operating room. Today they offer good magnification without significant aberrations, sufficient illumination without excessive heat, and satisfying stability without sacrificing operational flexibility. The cameras attached to modern microscopes allow surgical procedures to be recorded in high-definition quality. With the appropriate attachments, it is possible for 2 assistants to visualize the same surgical field as the primary surgeon. Controls for releasing the magnetic brakes and adjusting magnification can either be placed on handles or on a pedal. Some microscopes even have an autofocus feature. Yet, despite these impressive engineering achievements, there is undoubtedly opportunity for continued innovation.

Sophisticated imaging capabilities are being developed for today's operating microscopes. The Leica Company manufactures 2 modules, FL-400 and FL-800, which can be integrated into the Leica M525 OH4 (Fig. 5 left) or Leica M520 OH3 operating microscopes. The FL-400 module provides blue light illumination, which allows the surgeon to visualize malignant gliomas in patients who have been given 5 -aminolevulinic acid orally (Fig. 6). The FL-800 module offers intraoperative angiography by detecting intravenously injected ICG (Indocyanine Green) and projects the images to a monitor (Fig. 7) (Leica Microsystems, Inc. archives, 2009). Similar technology is offered by Carl Zeiss, Inc., whose neurosurgical microscopes include the OPMI Pentero (Fig. 5 right) and a ceiling-mounted version, the OPMI Pentero C. Infrared 800 technology in these models makes intraoperative angiography possible, while Blue 400 technology facilitates the detection of malignant gliomas. Both technologies

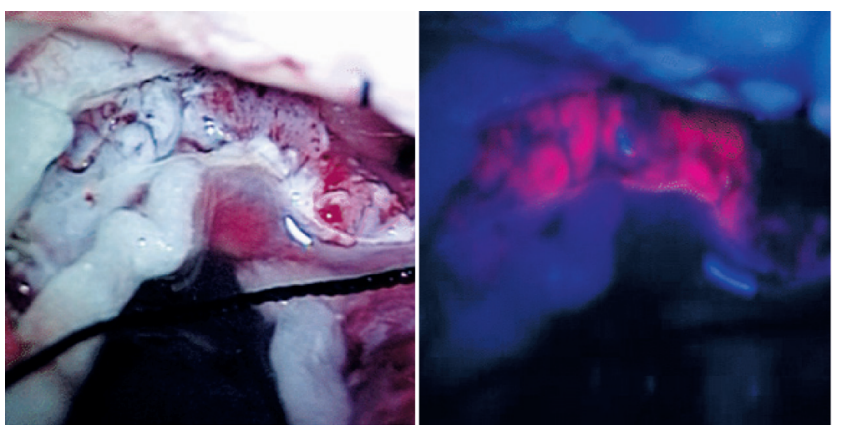

FIG. 6. Intraoperative photographs. Left: A malignant glioma under bright-field illumination. Right: The same malignant glioma imaged by a Leica FL-400 module under blue light. Courtesy of Leica Microsystems, Inc.

are available for the OPMI Pentero series (Carl Zeiss Archives, 2009).

As can be seen from the above discussion, modern microscopes have already started to combine multiple visualization techniques. In the near future, this trend will accelerate. We are not so far from microscopes that can display MR images, angiograms, and CT scans simultaneously and combine the information intraoperatively. Such real-time access to multiple types of imaging data will potentially aid in the spontaneous decision making of the surgeon in the operating room.

\section{The Next Step for the Operating Microscope}

In $47 \mathrm{BC}$, Julius Caesar is said to have used these words to describe his victory over Pharneces II of Pontus in the Battle of Zela, Turkey: "Veni, vidi, vici" ("I came, I saw, I conquered"). ${ }^{15,51}$ This same motto may be loosely applied to modern neurosurgery in its battle against disease. "Veni" could be interpreted as the neurosurgical approach to gain access to the lesion. "Vidi" could be interpreted as visualization modalities (such as radiography, MR imaging, CT, or microscopy). Finally, "vici" could correspond to a successful surgical outcome.

From the day that the microscope entered the operating room, the size, focusing, and flexibility of the microscope have continually presented operational challenges, and solutions to these have often caused new problems. For example, loupes can overcome the bulk of a microscope, but they are limited by their nonadjustable focus and low magnification. Loupes with increased magnification introduce the problem of stability, because even slight movements of the surgeon's head will cause the surgical field to be out of focus. Autofocus loupes could be used to overcome this problem. Because the depth of field at high magnifications is very small, however, an autofocus system faces the challenge of determining which focal plane is of interest to the surgeon at any given moment.

One method for addressing this problem would be to use a camera or a miniradar specifically targeted to follow the tip of a surgeon's microinstruments. Such a system could automatically adjust the focus of the loupe or microscope by continuously measuring the distance between an objective and the instrument's tip. In this way, a surgeon could maintain focus at the desired site while 


\section{History of the operating microscope}
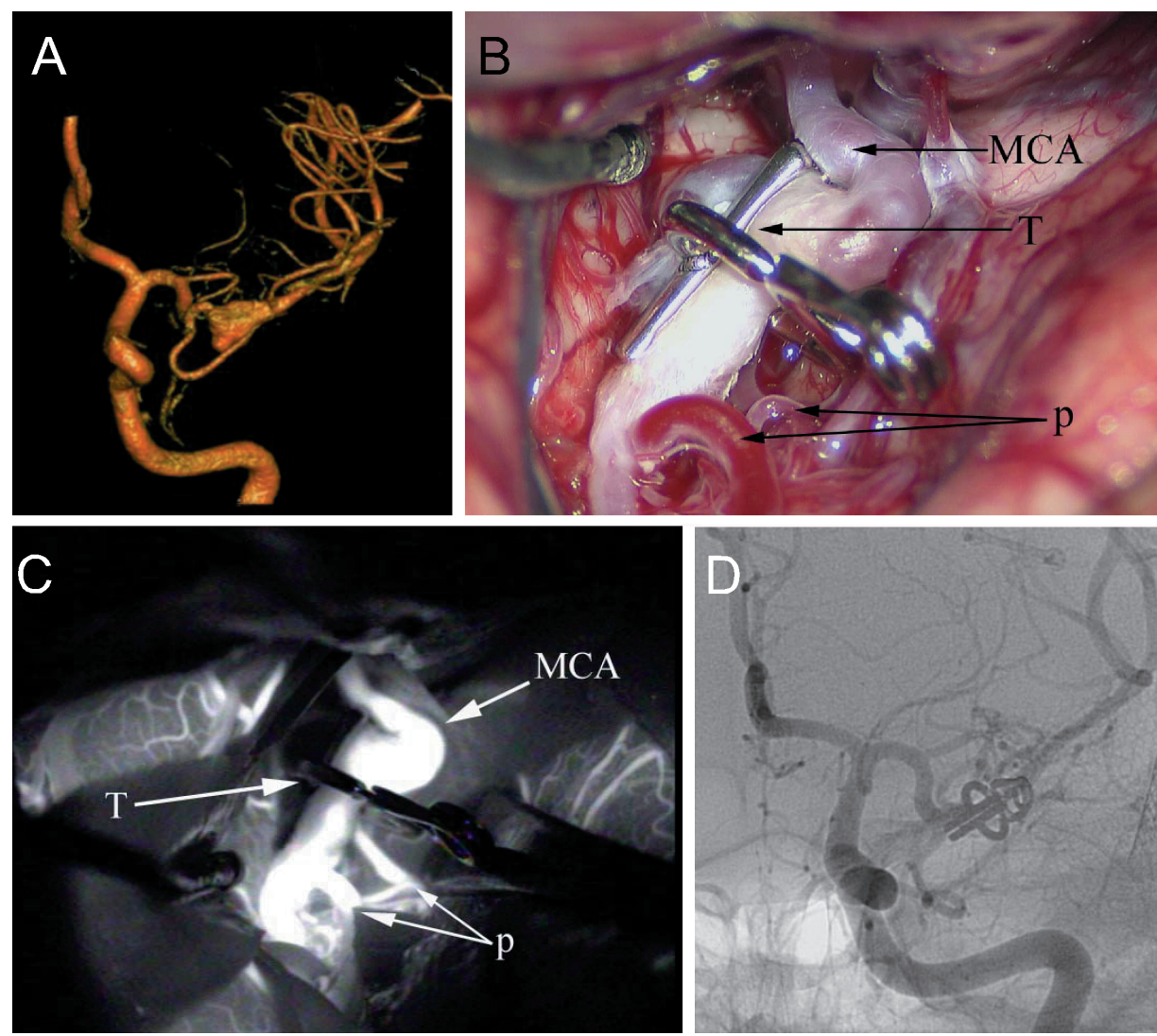

FIG. 7. A: Preoperative angiogram obtained in a 21-year-old patient showing a fusiform aneurysm of the left $M_{1}$ segment of the middle cerebral artery (MCA). B: Intraoperative photograph obtained under normal bright-field illumination. C: Surgical image of intraoperative angiography with indocyanine green dye after clipping, visualized by an FL-800 module. D: The postoperative angiogram correlates well with the intraoperative finding using indocyanine green dye injection. $p=$ medial lenticulostriate arteries; T = Yaşargil T-bar clip.

being free from manipulating traditional focus controls. Combining this type of autofocus with the use of a loupe would additionally allow the surgeon's hands to also be free from microscope movement controls.

It has been estimated that surgeons may spend up to $40 \%$ of their total time in surgery making adjustments to the microscope. ${ }^{66}$ The future development of technologies such as surgical instrument tracking autofocus will thus have the potential to significantly decrease surgical duration and also increase the performance of the surgeon.

\section{Disclaimer}

The authors report no conflict of interest concerning the materials or methods used in this study or the findings specified in this paper.

\section{References}

1. Abrahams P: The first 300 years of binocular telescopes. http://www.europa.com/ telscope/bintlhst.txt [Accessed 9 July 2009]

2. Agutter PS, Wheatly DN: Thinking About Life: The History and Philosophy of Biology and Other Sciences. New York: Springer, 2008, p 17

3. Aikin J, Enfield W, Nicholson, Johnston W, Morgan T: General Biography; or, Lives, Critical and Historical, of the
Most Eminent Persons of All Ages, Countries, Conditions, and Professions, Arranged According to Alphabetical Order, Vol 2. London: G. G. and J. Robinson, 1801, p 655

4. Anonymous: The Contemporary Review. London: A Strahan, 1875, pp 610-622

5. Balchin J: Science. New York: Enchanted Lion Books, 2003, pp 62-63

6. Bancroft E: Experimental Researches Concerning the Philosophy of Permanent Colours. Philadelphia: T Dobson, $1814, \mathrm{p} 332$

7. Barraquer JI: The history of the microscope in ocular surgery. J Microsurg 1:288-299, 1980

8. Barraquer JI, Barraquer J, Littman H: A new operating microscope for ocular surgery. Am J Ophthalmol 63:90-97, 1967

9. Behrman D: Solar Energy: The Awakening Science. Great Britain: Routledge \& Kegan Paul Ltd, 1979, pp 33-34

10. Brewster D: The Edinburgh Journal of Science. Edinburgh: Thomas Clark, 1831, pp 169-179

11. Carpenter WB, Dallinger WH: The Microscope and Its Revelations. Philadelphia: P. Blackiston's Sons and Co., 1901, pp $122-125$

12. Clarke AR, Eberhardt CN: Microscopy Techniques for Materials Science. Cambridge: Woodhead Publishing Ltd., 2002, pp 58-60

13. Crisp F, Bennett AW, Bell FJ, Mayall J, Hebb RG, Thomson JA: Journal of the Royal Microscopical Society. London \& Edinburgh: Williams \& Norgate, 1888, p 109

14. Croft WJ: Under the Microscope. Singapore: World Scientific, 2006, pp 7-8 
15. Dodge TA: Caesar. Cambridge, MA: Da Capo Press, 1997, pp 604-619

16. Doft MA, Widmann WD, Hardy MA: Under a microscope: Julius H. Jacobson, MD (1927-). J Surg Educ 65:316-319, 2008

17. Drake S: Galileo at Work: His Scientific Biography. New York: Courier Dover Publications, 2003, pp 356-357

18. Drake S: Galileo's first telescopic observations. Journal for the History of Astronomy 7:153-168, 1976

19. Ewert D: A General Introduction to the Bible: From Ancient Tablets to Modern Translations. Grand Rapids, MI: Zondervan, 1990, p 176

20. Field JV, James FAJL: Renaissance and Revolution: Humanists, Scholars, Craftsmen and Natural Philosophers in Early Modern Europe. London: Cambridge University Press, 1997, p 232

21. Freedheim DK: Handbook of Psychology, Vol 1. Hoboken, NJ: John Wiley and Sons, 2003, pp 91-92

22. Garrison FH: An Introduction to the History of Medicine. Philadelphia: WB Saunders Company, 1913, p 170

23. Gelberman RH: Microsurgery and the development of the operating microscope. Contemp Surg 13:43-46, 1978

24. Guenther AH: International Trends in Applied Optics. Bellingham, WA: SPIE Press, 2002, p 645

25. Hannavy J: Encyclopedia of Nineteenth-Century Photography. Boca Raton, FL: CRC Press, 2008, pp 1, 1521-1522

26. Harris CA, Blandy AA, Piggot AS: American Journal of Dental Science, Vol 5. Philadelphia: Lindsay \& Blackiston, $1855, \mathrm{p} 131$

27. Healy JF: Pliny the Elder on Science and Technology. New York: Oxford University Press, 1999, pp 1-3, 44, 147

28. Helden AV: Measuring the Universe. Chicago: University of Chicago Press, 2005, p 118

29. Herbermann CG, Pace EA, Shahan TJ, Pallen CB, Wynne JJ: The Catholic Encyclopedia: An International Work of Reference on the Constitution, Doctrine, Discipline, and History of the Catholic Church, Supp. 1, Vol 17. New York: Encyclopedia Press, 1913, p 222

30. Hoerenz P: Magnification: loupes and the operating microscope. Clin Obstet Gynecol 23:1151-1162, 1980

31. Huerta RD: Giants of Delft. Lewisburg, PA: Bucknell University Press, 2003, pp 30-32

32. Carboni G: A glass-sphere microscope. http://www.funsci. com/fun3_en/usph/usph.htm\#3 [Accessed 9 July 2009]

33. Ilardi V: Renaissance Vision from Spectacles to Telescopes. Philadelphia: American Philosophical Society, 2007, pp 276277

34. Kalderon AE: The evolution of microscope design from its invention to the present days. Am J Surg Pathol 7:95-102, 1983

35. King HC, Jones HS: The History of the Telescope. New York: Courier Dover Publications, 2003, p 25

36. Kingslake R: A History of the Photographic Lens. London: Academic Press, 1989

37. Kriss TC, Kriss VM: History of the operating microscope: from magnifying glass to microneurosurgery. Neurosurgery 42:899-907, 1998

38. Lindberg DC: Theories of Vision from al-Kindi to Kepler. Chicago: University of Chicago Press, 1981, pp 18, 22, 58-68

39. Louw DF, Sutherland GR, Schulder M: From microscopic to astronomic, the legacy of Carl Zeiss. Neurosurgery 52: 668-674, 2003

40. Lulek T, Lulek B, Wal A: Symmetry and Structural Properties of Condensed Matter. Poland: World Scientific, 2003, pp 3-4

41. Lumley JSP: Microsurgery. Practitioner 226:1723-1726, 1982

42. Norris WF, Oliver CA: System of Diseases of the Eye, Vol 2. Philadelphia: JB Lippincott, 1897, pp 57-58
43. Nylén CO: The microscope in aural surgery, its first use and later development. Acta Otolaryngol Suppl 116:226-240, 1954

44. Pliny the Elder: Natural History: A Selection. Healy JF, trans. London: Penguin Classics, 1991

45. Porter R, Linberg DC, Numbers RL, Nye MJ, Ross D: The Cambridge History of Science: Eighteenth-Century Science. New York: Cambridge University Press, 2003, pp 522523

46. Quekett JT, Quekett J: A Practical Treatise on the Use of the Microscope: Including the Different Methods of Preparing and Examining Animal, Vegetable, and Mineral Structures. London: Bailliere, 1855, pp 2-3

47. Rochow TG, Tucker PA: Introduction to Microscopy by Means of Light, Electrons, X Rays, or Acoustics. New York: Springer, 1994, pp 1-4

48. Rohr M: Die binokularen Instrumente: nach Quellen. Berlin: J Springer, 1907

49. Roxburgh DJ: Prefacing the Image: The Writing of Art History in Sixteenth-Century Iran. The Netherlands: Brill Academic Publishers, 2001

50. Sampaolesi R, Zarate J: The Glaucomas: Pediatric Glaucomas. New York: Springer, 2009, pp 128-129

51. Schmitt CB, Skinner Q, Kessler E, Kraye J: The Cambridge History of Renaissance Philosophy. Cambridge: Cambridge University Press, 1990, pp 271-272

52. Schultheiss D, Denil J: History of the microscope and development of microsurgery: a revolution for reproductive tract surgery. Andrologia 34:234-241, 2002

53. Schulze F: [Carl Wilhelm von Zehender (1819-1916) - authentic data from his life.] Gesnerus 47:59-66, 1990 (Ger)

54. Serdyuk IN, Zaccai NR, Zaccai J: Methods in Molecular Biophysics. Cambridge: Cambridge University Press, 2007, pp 627-628, 885

55. Shambaugh GE Jr: Fenestration; past, present and future. Ann Otol Rhinol Laryngol 64:149-160, 1955

56. Singh S: Fundamentals of Optical Engineering. New Delhi: Discovery Publishing House, 2009, pp 4-8, 12-13, 17, 25

57. Splinter R, Hooper BA: An Introduction to Biomedical Optics. London: Taylor \& Francis Group, 2007

58. Steadman P: Vermeer's Camera. New York: Oxford University Press, 2002, p 53

59. Suleri ZA, Ahmad Z: Influence of Islam on World Civilization. Karachi: Royal Book Co., 1994, p 222

60. Tamai S: History of microsurgery-from the beginning until the end of the 1970s. Microsurgery 14:6-13, 1993

61. Tamai S, Usui M, Yoshizu T: Experimental and Clinical Reconstructive Microsurgery. New York: Springer, 2003, pp 4-6

62. Tokaty GA: A History and Philosophy of Fluid Mechanics. New York: Courier Dover Publications, 1994, pp 21-22

63. Troutman RC: The operating microscope: past, present and future. Trans Ophthalmol Soc U K 87:205-218, 1967

64. Volkmann H: Ernst Abbe and his work. Appl Opt 5:17201731,1966

65. Wade NJ: A note on the history of binocular microscopes. Perception 10:591-592, 1981

66. Yaşargil MG: Microneurosurgery, Vol 1. Stuttgart: Georg Thieme Verlag, 1984, pp 208-211

Manuscript submitted May 15, 2009.

Accepted June 30, 2009.

Address correspondence to: Mustafa K. Başkaya, M.D., Department of Neurological Surgery, University of Wisconsin, CSC K4/828, 600 Highland Avenue, Madison, Wisconsin 53792. email: m.baskaya@neurosurg.wisc.edu. 